\section{LATERAL LIGAMENT COMPLEX ANKLE SPRAIN EPIDEMIOLOGY: UNITED STATES COLLEGE ATHLETES, 2009/10-2014/15}

${ }^{1}$ Karen G Roos, ${ }^{1}$ Aristarque Djoko, ${ }^{2}$ Erik Wikstrom, ${ }^{1}$ Thomas P Dompier, ${ }^{1}$ Zachary Y Kerr. ${ }^{1}$ Datalys Centre for Sports Injury Research and Prevention, USA; ${ }^{2}$ University of North Carolina at Chapel Hill, USA

\subsection{6/injuryprev-2016-042156.485}

Background Lateral ligament complex (LLC) ankle sprains are among the most common injuries in United States (US) college athletes. But, there is limited information about the specific epidemiology of such injuries.

Methods De-identified data from the National Collegiate Athletic Association (NCAA) Injury Surveillance Program (ISP) was analysed for 25 sports from the 2009/10-2014/15 academic years. Analyses were limited to injuries diagnosed as LLC sprains. Descriptive statistics include frequencies, rates per 10,000 athlete-exposures (AE), and rate ratios (RR) with 95\% confidence intervals (CI).

Results LLC sprain was the most common injury diagnosis in 25 NCAA sports, with 2,429 reported in the sample from the study period. This results in a LLC sprain rate of 4.95/10,000 AEs and a national annual estimate of 16,022 LLC sprains in NCAA athletes. The sports with the highest LLC sprain rates were men's/ women's basketball (11.96 and 9.50/10,000 AE, respectively), and men's/women's soccer (7.43 and 8.36/10,000 AE, respectively). Football had the largest national estimate in NCAA athletes $(3,606$ per year), despite having a moderate LLC sprain rate (6.87/10,000 AE). Most LLC sprains occurred during practices (57.3\%); however, the LLC sprain rate was higher in competition than in practice $(\mathrm{RR}=3.29$; 95\% CI: 3.03-3.56). Overall, $44.3 \%$ of LLC sprains required participation restriction time under 24 hours; 33.7\%, 1-6 days; 15.7\%, 7-21 days; and 3.6\%, over 21 days. In total, $11.9 \%$ of LLC sprains were recurrent. The sports with the largest proportion of recurrent LLC sprains were women's basketball and women's outdoor track and field (both 21.1\%). The most common injury mechanisms for LLC sprains were player contact $(41.4 \%)$, and non-contact $(27.4 \%)$.

Conclusions LLC sprains are the most common injury in US college athletes. Nearly 20\% require at least 7 days of participation restriction time. Future research and interventions should address men's/women's soccer and basketball.

\section{SURVIVAL ANALYSIS IN SPORTS INJURY RESEARCH: A SYSTEMATIC REVIEW}

Muhammad Akram, Caroline F Finch, Lauren V Fortington. Federation University Australia

\subsection{6/injuryprev-2016-042156.486}

Background International literature recognises that sports people who have sustained an injury have a high likelihood of a subsequent injury, either of the same type again or a different one. Taking into account the dependency of subsequent injuries within athletes is important, otherwise, results have greater precision than is warranted and there is possible biassing of results away from the null. Survival methods for recurrent events data can be applied to take into account the potential statistical relationships between subsequent injuries. Various survival analysis approaches exist and the selection of a correct model is important. The aim of this systematic review was to identify and evaluate the appropriate use of survival analysis methods in sports injury incidence studies.
Methods The review was performed and reported according to the Preferred Reporting Items for Systematic Reviews and Metaanalyses (PRISMA) Statement, comprising a traditional systematic search of literature and a hand search of key sports medicine journals. Descriptive data on the studies were extracted (e.g. aim, setting, follow up) along with detailed information on the reported survival analysis methods. The appropriateness of selected models, and their reporting, were examined in-depth.

Results There were 699 publications screened from which 123 were included for further review. Studies were mainly focused on the reported time to first injury $(n=53 \%)$ or the time to recover/return to play after injury (19\%). Recurrent or subsequent injuries were only considered in $10 \%$ of papers. Graphical approaches (Kaplan-Meier curves) were most commonly used (51\% of studies), along with simple univariate $(30 \%)$ and Coxregression techniques (88\%).

Conclusions While a number of researchers have used survival methods for analysis of sports injury data, there is scope for improvement in the statistical approaches used and, specifcally, in the reporting of subsequent injuries.

\section{PILOTING INJURY SURVEILLANCE SYSTEM IN SAUDI ARABIA}

Alanazi Faisal, Hussain Arif. Injury and Accident Prevention Program, Ministry of Health Kingdom of Saudi Arabia

\subsection{6/injuryprev-2016-042156.487}

Background The Injury \& Accidents Prevention Program (IAPP) of Saudi Health Ministry designed an Injury Surveillance System with the aim to gather regular ongoing information for prevention and control of injuries and efficient use of resources. World Health Organisation, Ministry of Interior, Traffic Police, Saudi Red Crescent and other partners were involved during the process.

Method This system was piloted in selected health regions, involving a multistage stratified random sample. In first stage, half of 20 health regions were selected, followed by random selection of 14 health facilities, stratified by sub-sector and facility level health. Two physicians were trained from each selected health facility on the predesigned tool and procedures; they collected the data and regularly transferred to IAPP through Regional Coordinators, for entry and analysis.

Results Seven health regions reported 10008 injuries including $74.5 \%$ males (mean age $23.3 \pm 15.9$ ); mostly (81\%) 35 years or less. About $76 \%$ injury cases were unintentional and $35 \%$ occurred at home followed by workplace (20\%) and roads $(19 \%)$. Less than $5 \%$ of the injuries were severe in nature and $25 \%$ moderate; mainly occurred due to falls $(31 \%)$, blunt force $(20 \%)$ and traffic crashes (15\%). Injuries mainly resulted into closed wounds (44\%), open wounds (29\%) and fractures (14\%).

Discussion Pilot was intended to test the system and identify procedures that could be improved before scaling up; at this stage the cases do not represent total injuries reporting to health facilities. Implementing the surveillance system across the Kingdom would be challenging, but will generate useful information for decision making.

Conclusion The pilot identified efficiency of the surveillance system and its capacity to capture injury cases reporting to health facilities, but necessitates including paramedics for workload distribution; and requires more ownership form regional offices. 


\section{Older People Safety}

Post Mon 1.10

\section{THE IMPLEMENTATION OF FALLS PREVENTION FOR OLDER PERSONS IN RESIDENTIAL AGED CARE THROUGH BUILDING DESIGN}

${ }^{1}$ Peter Bewert, ${ }^{2}$ Sharon Callister, ${ }^{3}$ Rohan McDonald. ${ }^{1}$ Executive Manager Care Services the Salvation Army Aged Care Plus; ${ }^{2}$ Chief Executive Officer the Salvation Army Aged Care Plus; ${ }^{3}$ Executive Manager Capital Projects, the Salvation Army Aged Care Plus

\subsection{6/injuryprev-2016-042156.488}

Background Building design features of residential homes typically follow a medical model in design. This design often includes 'grab rails' in common areas to assist older persons with their mobility. This however provides an institutionalised feel rather than a home like environment. Contemporary building design can engineer out these institutionalised falls prevention measures and result in contemporary features that reduce falls incidence.

Description of problem The instance of falls in the elderly are a major contributing factor to physical decline in health status and subsequent increase of physical care needs in a residential aged care environment. The Salvation Army Aged Care Plus has adopted a person centred approach to building design to ensure the living environment is more homely. The building design has engineered rest points and other design features which has substantially reduced the incidence of falls in the elder population group within the environment.

Results Results have indicated a reduction in falls, an increase in physical agility, mobility and dexterity in combination with allied health intervention models. These results have been consistently reviewed and tested experientially over two recent aged care home commissioning of similar size, nature and resident functional status.

Conclusions The strategic design of the living environment can assist with an aesthetically pleasing home like environment for the older person living in residential aged care whilst substantially reducing falls risk. This outcome impacts on quality of life experience and satisfaction of the older person in the residential care environment.

\section{ENSURE SAFETY FROM AGRICULTURAL WORK OF ELDERLY IN JAPAN}

'Masahiro Kawasaki, ${ }^{1}$ Hiromi Kawasaki, 'Satoko Yamasaki, ${ }^{1}$ Akihiro Kihara, ${ }^{1}$ Susumu Fukita, ${ }^{2}$ Mika Nishiyama, ${ }^{3}$ Pete D'Angelo. ${ }^{1}$ Hiroshima University, Japan; ${ }^{2}$ Hiroshima Bunkyo Women's University, Japan; ${ }^{3}$ Doi Clinic, Japan

\subsection{6/injuryprev-2016-042156.489}

Background Japanese agriculture is often a collection of small landowners. Farmland is maintained by men who also work for a company. Agricultural work continues even after retirement. It is important for elderly people to protect themselves from accidents. Agricultural areas are sparsely populated making health maintenance even more important. The purpose of this study is to analyse the understanding and physical status of elderly farmers.

Methods Participants of an agriculture company, a mutual aid organisation, in rural areas. A questionnaire, interview and physical measurement was conducted. Analysis was performed using the t-test.
Results Questionnaire; 119 farmers (82 men and 37 women) average age 65.8 years old.

64 had knee pain (54.2\%), 55 had waist pain (46.6\%).(When sleeping facing up, there was waist pain: 43, 46.8\%)(Waist pain when bending: 47, 37.9\%)(Painful to divert the waist: 52, $54.8 \%$ ) (Painful to twist the waist: 35, 28.2\%) (Painful in the same position: 70, 68.5\%) Physical function; bending: pain in the knee: $34.9 \mathrm{~cm}$ (no pain: $29.9 \mathrm{~cm})(\mathrm{p}=0.02)$, best walking 5.0 seconds $(5.5$ seconds) $(\mathrm{p}=0.048)$. Normal walking 10 metres; pain in the waist: 7.64 seconds, (no pain: 7.00 seconds) $(\mathrm{p}=0.049)$.

Conclusions Performing agricultural work continues in order to maintain the ancestral farmland. Farmers of advanced age have problems with pain in the knee and waist. Their bodies have weakened due to ageing. They were feeling pain when they bend, stretch or twist. There is a fear of falling when trying to stand. Scaffolding around the work area should be in place. Before and after agricultural work, stretching exercise is required. However, stretching exercise is difficult for farmers because of the pain in the knee and waist. Methods for easily achievable exercise need to be designed and taught to farmers.

\section{PREDICTORS OF OLDER ADULTS' PARTICIPATION IN BALANCE CLASS TO PREVENT FALLS: CASE-CONTROL STUDY}

${ }^{1}$ Dustin W Currie, ${ }^{2}$ Sallie R Thoreson, ${ }^{3}$ Lauren Clark, ${ }^{1}$ Cynthia W Goss, ${ }^{4}$ Mark J Marosits, ${ }^{1}$ Carolyn G DiGuiseppi. ${ }^{1}$ University of Colorado Anschutz Medical Campus, USA; ${ }^{2}$ Colorado Department of Public Health and Environment, USA; ${ }^{3}$ University of Utah, USA; ${ }^{4}$ Worldways Social Marketing, USA

\subsection{6/injuryprev-2016-042156.490}

Background Falls are the leading cause of injury morbidity and mortality in older adults. Exercise, including balance and strength training, decreases fall risk, but few older adults exercise as recommended. We examined factors associated with older adults' participation in balance classes.

Methods This case-control study was nested in a controlled trial in which churches were randomly assigned to a social marketing program to encourage older adults to attend N'Balance classes or to no intervention. Eligible subjects were study church congregants aged $\geq 60$ who completed a study survey. Cases included all eligible subjects who attended an N'Balance class during the study period; controls were congregants randomly selected to receive a survey who did not attend a balance class in this period. Study church leaders provided information about themselves and their church. Individual and church level characteristics were examined using logistic regression to determine the independent effect of social marketing and identify additional predictors of balance class participation.

Results After accounting for individual and church level differences, cases ( $\mathrm{n}=173$ N'Balance participants) were much more likely than controls $(\mathrm{n}=270)$ to attend churches that received the social marketing program (adjusted OR [aOR]: 20.62 [95\% CI: 9.55, 44.54]). Cases were older (aOR per year of age: 1.06 $[1.03,1.10])$, more likely to be female (aOR: 3.07 [1.74, 5.42]), and more frequently experienced 'near falls' (aOR: 1.98 [1.44, 2.72]). Cases were also more likely to attend a church with an older religious leader (aOR per year of age: 1.04 [1.01, 1.07]), located in a rural area (aOR: 1.89 [1.11, 3.22]).

Conclusions Church-based social marketing was strongly associated with increased uptake of balance classes for reducing fall risk, particularly among certain high-risk groups. Church-based 